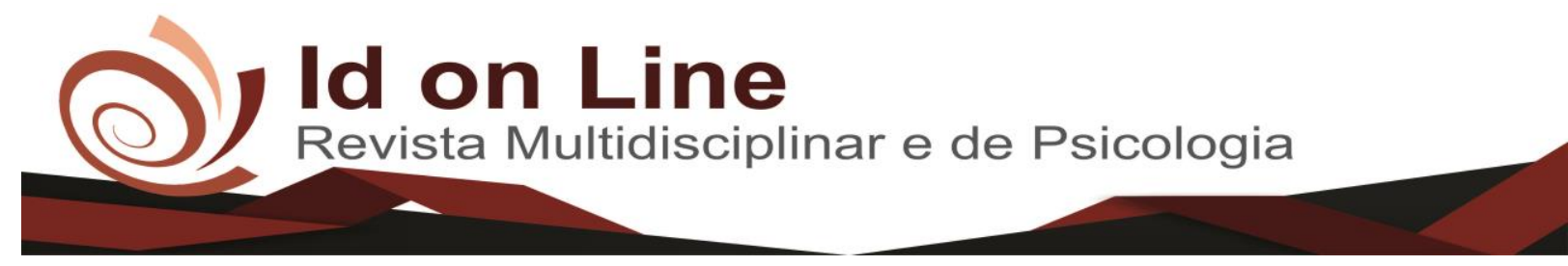

Relato de Caso

\title{
Saúde Mental na Prática
}

Yana Camila Brasil Marques ${ }^{1}$

Resumo: A Saúde Mental no Brasil ainda é um tema cheio de estigmas pela sociedade brasileira. Apesar de haver a luta anti - manicomial há 30 (trinta) anos, ainda existem muitos preconceitos da população, da família de clientes em sofrimento psíquicos e até mesmo destes indivíduos que não tem seus direitos e suas autonomias respeitadas. O presente trabalho foi desenvolvido durante o primeiro estágio curricular do $3^{\circ}$ ano do Curso Técnico em Enfermagem de uma Escola Estadual de Educação Profissional no interior do Estado do Ceará na área de Saúde Mental. O objetivo é de divulgar as atividades realizadas durante o estágio em Saúde Mental no CAPS II de um município do interior do Ceará. No decorrer no estágio, foram desenvolvidas atividades de ludoterapia, musicoterapia, como: a Sala de Espera Animada - SEA, a Calçada Amiga - CAMI (idealizadas/inspiradas no método de trabalho do médico americano Patch Adams) e atividades que desenvolvessem a humanização dos alunos no serviço e nos atendimentos para com os usuários do serviço.

Palavras Chave: Saúde Mental; Enfermagem; Ludoterapia; Humanização; Estágio.

\section{Mental Health in Practice}

Abstract: Mental Health in Brazil is still a theme full of stigmas by Brazilian society. Although there has been an anti - manicomial fight for thirty (30) years, there are still many prejudices of the population, the family of suffering clients and even those individuals who do not have their rights and autonomy respected. The present work was developed during the first curricular stage of the 3rd year of the Technical Course in Nursing of a State School of Professional Education in the interior of the State of Ceará in the area of Mental Health. The objective is to disclose the activities carried out during the Mental Health Internship in the CAPS II of a municipality in the interior of Ceará. In the course of the internship, activities of ludoterapia and music therapy were developed, such a Sala de Espera Animada - SEA, Calçada Amiga CAMI (idealized / inspired by the method of work of the American Doctor Patch Adams) and activities that developed the humanization of students in the service and in the consultations with the users of the service.

Keywords: Mental health; Nursing; Ludoterapia; Humanization; Internship.

\section{Introdução}

A Saúde Mental do século XXI está muito diferente da do século passado, antigamente as pessoas tidas como "loucas" eram enclausuradas em hospitais psiquiátricos e até mesmo nos fundos das casas dos familiares e tratadas como animais, algumas viviam amarradas, sem comida, sem uma higiene favorável.

\footnotetext{
${ }^{1}$ Enfermeira Especialista em Docência no Ensino Superior e em Saúde Mental. Professora EMI na EEEP Prof. Emmanuel Oliveira de Arruda Coelho - Granja-Ceará. Contato: yanacariri@gmail.com
} 
Nos hospitais, a realidade não era tão diferente, pessoas eram amarradas nas camas e ali mesmo faziam suas necessidades fisiológicas, sem falar nos tratamentos tidos como eficientes e necessários para o tratamento como: choqueterapia, lobotomia, insulinoterapia, ... Essas pessoas tinham seus direitos violados, sua dignidade, sua autonomia. E, há trinta anos, isso vem mudando, com a Reforma Psiquiátrica - Luta Anti-Manicomial, com a redução progressiva dos hospitais psiquiátricos e a criação dos Centros de Atenção Psicossocial - CAPS, Hospitais Dia, Residências Terapêuticas... Esses pacientes estão voltando a viver, estão voltando ao convívio com a sociedade. Se tempos atrás, o tratamento era praticamente a base de medicamentos, hoje, além dos medicamentos, existem as rodas de conversas terapêuticas, artesanatos, aulas de canto, teatro, dança e várias outras atividades que ajudam os usuários do serviço a se expressarem, a desenvolverem um relacionamento com o próximo, a serem independentes e principalmente, a se inserirem na sociedade, um direito que lhes foi proibido e apesar de tantos avanços ainda possui muitas dificuldades devido aos estigmas e preconceitos.

O presente estudo foi elaborado com o intuito de divulgar as atividades desenvolvidas durante o Estágio Curricular do $3^{\circ}$ Ano do Curso Técnico em Enfermagem em Saúde Mental. O estágio iniciou em 08 de Maio de 2017 e encerrou em 15 de Dezembro de 2017, houve 05 (cinco) equipes que estagiaram durante seis semanas no Centro de Atenção Psicossocial CAPS II em uma cidade do interior do Ceará.

O estigma ainda presente na sociedade acerca do cuidado em saúde mental e principalmente para com o paciente motivaram a realização do estudo.

Das diferentes atividades desenvolvidas entre a professora e os alunos, ocorreram atividades em que os alunos participaram ativamente como a Sala de Espera Animada - SEA e Calçada Amiga - CAMI, além de outras prestações de serviços para com o cliente em sofrimento psíquico e o familiar/acompanhante/cuidador.

A justificativa do trabalho foi de observar se as atividades propostas colaboraram aos pacientes em sofrimento psíquico a interagirem com o próximo, se ajudaram a diminuir ou extinguir o preconceito que a sociedade tem em relação ao tratamento em Saúde Mental e ao paciente com problemas mentais, além de averiguar se as atividades propostas desenvolveram a humanização dos alunos/estagiários.

163 Id on Line Rev. Mult. Psic. V.12, N. 40. 2018 - ISSN 1981-1179 
Como Objetivo Geral de Identificar as atividades realizadas/a rotina durante o Estágio Curricular em Saúde Mental do $3^{\circ}$ Ano do Curso Técnico em Enfermagem, e como Específicos: Listar a rotina dos alunos desenvolvida durante o estágio em Saúde Mental no CAPS II; Divulgar a ação Calçada Amiga - CAMI e Difundir a ação Sala de Espera Animada - SEA.

\section{Referencial Teórico}

\section{Reforma Psiquiátrica No Brasil}

Ao final da II Guerra Mundial, vários movimentos de contestação do saber e práticas psiquiátricas se faziam notar no cenário mundial, dos quais se destaca a Psiquiatria de Setor na França, as Comunidades Terapêuticas na Inglaterra e a Psiquiatria Preventiva nos EUA. Eram movimentos de "reforma" da assistência psiquiátrica no sentido de apontarem para um rearranjo técnico-científico e administrativo da Psiquiatria, sem a radicalidade da desinstitucionalização, proposta pelo movimento italiano, a partir de 1960. (ROTELLI,et. al., 1990)

Compreendemos, portanto, a Reforma Psiquiátrica como um movimento, um processo histórico que se constitui pela crítica ao paradigma psiquiátrico clássico e pelas práticas que transformam/superam esse paradigma, no contexto brasileiro, a partir do final da década de 1970. Apresenta-se fundamentalmente como crítica à conjuntura nacional do sistema de saúde mental e, principalmente, como crítica estrutural à "instituição" - psiquiatria. Como processo histórico, insere-se numa totalidade complexa e dinâmica, portanto, também determinado nacionalmente pelo processo de redemocratização em curso no País a partir daquela época. (AMARANTE, 1995).

\section{Centro de Atenção Psicossocial - CAPS}

Os serviços substitutivos ao modelo hospitalocêntrico, o mais antigo modelo de cuidado ao portador de sofrimento psíquico, surgem na intenção de que este sujeito doente seja visto a partir de outro paradigma, o da reabilitação psicossocial, entendida como uma ação ampliada, 
que considera a vida em seus diferentes âmbitos: biológico, social, cultural, espiritual e familiar, objetivando, assim, a reinserção deste sujeito na sociedade. (SILVA, et. al., 2011)

As relações sociais que se desenvolvem no interior do hospital psiquiátrico são dominantes, evidenciando a hierarquia, subordinação, exclusão, expropriação do saber e a divisão do trabalho e dos saberes em especialidades. A implantação do modelo psicossocial tem o objetivo de reinserir o portador de transtorno psíquico em suas atividades diárias, tornando possível a interação com a família e comunidade em geral. (SILVA, et. al., 2011)

Desta forma, sob este novo olhar, surgem os serviços substitutivos ao hospital psiquiátrico, que se constituem em uma rede de atenção à saúde mental. Esta rede é constituída tanto pela atenção básica em saúde, como as unidades básicas de saúde, quanto pelos serviços especializados, incluindo ambulatórios de saúde mental, os Centros de Atenção Psicossocial (CAPS), hospital-dia, serviços de urgência e emergência psiquiátricas, leito ou unidade em hospital geral e serviços residenciais terapêutico. (SILVA, et. al., 2011)

Os Centros de Atenção Psicossociais (CAPS) são serviços de atenção diária em saúde mental, de caráter substitutivo ao hospital psiquiátrico. Têm a responsabilidade de atender pessoas com transtornos mentais severos e persistentes, trabalhando sob a lógica da territorialidade. Estes serviços são regulamentados pela portaria ministerial GM nº 336, de 19 de fevereiro de 2002. (SILVA, et. al., 2011)

O CAPS trabalha com equipe multiprofissional e as atividades desenvolvidas neste espaço são bastante diversificadas, oferecendo atendimentos em grupos e individuais, oficinas terapêuticas e de criação, atividades físicas, atividades lúdicas, arteterapia, além da medicação, que antes era considerada a principal forma de tratamento. Neste serviço, a família é considerada como parte fundamental do tratamento, tendo atendimento específico (grupal ou individual) e livre acesso ao serviço, sempre que se fizer necessário. (SILVA, et. al., 2011)

\section{Humanização}

Humanização é uma expressão de difícil conceituação, tendo em vista seu caráter subjetivo, complexo e multidimensional. Inserida no contexto da saúde, a humanização, muito mais que qualidade clínica dos profissionais, exige qualidade de comportamento. Dicionários da língua portuguesa definem a palavra humanizar como: tornar humano, civilizar, dar condição 
humana. Portanto, é possível dizer que humanização é um processo que se encontra em constante transformação e que sofre influências do contexto em que ocorre, só sendo promovida e submetida pelo próprio homem. (SIMÕES et. al., 2007)

Para Freyre (2004) a humanização estabelece-se como construção de atitudes éticoestético-políticas em sintonia com um projeto de co-responsabilidade e qualificação dos vínculos entre estes e os usuários na produção de saúde.

Para Vaitsman; Andrade (2005) a humanização é definida como a idéia de dignidade e respeito à vida humana, enfatizando-se a dimensão ética na relação entre pacientes e profissionais de saúde. É tratar com ética e respeito, o próximo, com o objetivo de valorizar holisticamente a vida do ser com quem se trabalha, se participa, e principalmente, se cuida.

\section{Descrição Metodológica}

Trata-se de um relato de experiência de caráter descrito que descreve a vivência/rotina das atividades desenvolvidas pela professora orientadora do estágio em Saúde Mental do Curso Técnico em Enfermagem de uma Escola Estadual de Educação Profissional no interior do Ceará no período de 08 de Maio de 2017 à 15 de Dezembro de 2017. Utilizou-se a metodologia participativa a qual propicia a articulação do aluno com os usuários do CAPS (HILDEBRAND, 2007). Essa metodologia pode ser compreendida como um processo contínuo, não estático, onde se apresenta como alicerce para construção de um trabalho participativo, conjunto e que precisa ser adaptado a cada momento de acordo com a população almejada (KUMMER, 2007). Juntamente a metodologia participativa fez-se uso da metodologia alternativa (GODIN, 1999). Por compreender que o ensino e nesse caso, o ensino de práticas de saúde transmitido através de dinâmicas, jogos e desafios, pode provocar uma assimilação de conceitos de forma mais efetiva e contínua e essa prática saudável pode ocorrer através de ações ou discussões sobre o assunto. (YAMAZAKI; YAMAZAKI, 2006).

Para esse trabalho utilizou-se da primeira etapa de sensibilização e mobilização, da segunda etapa de diagnóstico participativo e a terceira de execução das atividades.

A partir da metodologia alternativa é possível coletar informações por meio de observação das interações grupais partindo de três temáticas. Nas ações desenvolvidas abordou- 
se a humanização, empatia e respeito para com o próximo no objetivo de extinguir o preconceito dos alunos para com o cliente em sofrimento psíquico.

\section{Descrição da Experiência}

Concomitante a essas temáticas foram verificadas as pressões arteriais, realizado orientações acerca da Hipertensão e Hipotensão, além de hábitos saudáveis de alimentação dos pacientes e acompanhantes; Desenvolvimento da Calçada Amiga - CAMI e da Sala de Espera Animada - SEA e Ludoterapia, além de os alunos desenvolverem atividades de prestação de serviços no Setores da Farmácia, Recepção e auxiliarem a Enfermeira em procedimentos diversos.

Ao final do estágio, foi desenvolvido o relatório final/portfólio, relato de experiência constando as atividades elaboradas, documentos fotográficos e cinematográficos das ações.

A pesquisa foi realizada em um município do interior do Ceará em uma Escola de Educação Profissional do Estado do Ceará e no CAPS. Desse local (Escola) se deu devido o mesmo possuir o Curso Técnico em Enfermagem e estar desenvolvendo desde o mês de Maio do respectivo ano, o primeiro estágio curricular em Saúde Mental. E, quanto ao CAPS ser o local de estágio em Saúde Mental escolhido pela Escola.

O presente estudo foi cadastrado no Sistema Nacional de Informações sobre Ética em Pesquisa envolvendo Seres Humanos (SISNEP) e encaminhado ao Comitê de Ética e Pesquisa (CEP) da Universidade Estadual Vale do Acaraú - UVA - em Sobral - CE. Além disso, foi solicitada a anuência do Diretor do local de estudo (Escola Profissionalizante) para a realização da pesquisa e da Coordenadora do Centro de Atenção Psicossocial.

O estágio em Saúde Mental iniciou em 08 de Maio de 2017 e encerrou dia 15 de Dezembro de 2017, o estágio ocorria de segunda à sexta no período matutino de 07h30 às 11h30. Ao todo foram 05 (cinco) equipes que estagiaram no CAPS, totalizando 37 (trinta e sete) alunos de idades entre 17 e 18 anos.

O estágio iniciava às $07 \mathrm{~h} 30$, primeiramente, os alunos assinavam as frequências em seguida, a orientadora, repassava as orientações do dia e/ou algum texto ou atividade altruísta breve para ser desenvolvida com os alunos até às $08 \mathrm{~h}$. 
A Calçada Amiga - CAMI foi idealizada seguindo os passos do método de trabalho do médico americano Patch Adams e era realizada inicialmente, uma vez na semana, nas sextasfeiras, a partir da terceira semana de estágio era realizada três vezes na semana (quarta-feira, quinta-feira e sexta-feira). Iniciava-se às $07 \mathrm{~h} 45$ e encerrava-se às $08 \mathrm{~h}$. Os alunos e a professora orientadora do estágio ficavam na calçada em frente ao CAPS distribuindo abraços, sorrisos e desejos de bom dia para a população sempre com uma música animada de fundo, com balões coloridos, mini alto falante, apitos, etc. $\mathrm{O}$ intuito principal era de mostrar à população que o tratamento desenvolvido no CAPS, o tratamento em Saúde Mental, não deve ser visto como um tabu, como algo hostil. Através dessa atividade havia tentativas de diminuir o preconceito para com a Saúde Mental e com o paciente em sofrimento psíquico, além de ajudá-lo na reinserção na sociedade.

Às 08h, iniciava-se a Sala de Espera Animada - SEA que também foi idealizada seguindo os passos do método de trabalho do médico americano Patch Adams e se dividia em quatro etapas: $1^{\text {a }}$ Etapa: Abordagem explicando a atividade de acolhimento e os benefícios aos clientes e acompanhantes do CAPS que buscavam atendimento no dia. Depois de serem convidados, todos faziam alongamentos simples; $2^{\mathrm{a}}$ Etapa: Dança (forró pé de serra, lambada, festa junina) com todos (alunos, funcionários, clientes e acompanhantes) que estavam na Sala

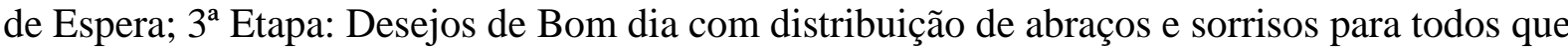
estavam presentes no estabelecimento e $4^{\mathrm{a}}$ e última Etapa: Palestra Educativa (com temas de Saúde eram escolhidos para ser estudados pelos alunos e este tema era difundido por uma semana, entre os temas estudados estavam: Hipertensão e Hipotensão; Tabagismo; Higiene Oral e Corporal; Doenças Psicossomáticas e Prevenção ao Suicídio).

Nas duas últimas semanas de estágio, todos os temas eram ministrados em um único dia (todos os alunos, se revezavam e palestravam sobre esses assuntos), durante toda a semana. $\mathrm{O}$ objetivo principal da SEA era de mostrar à sociedade que a pessoa em sofrimento psíquico é capaz de se divertir e de se relacionar com as pessoas à sua volta.

A SEA pode ser tida como uma atividade que combate o estigma social de que todo paciente com transtorno mental é perigoso e que não pode/deve se relacionar com as pessoas. A Sala de Espera Animada - SEA era realizada diariamente, de segunda-feira à sexta-feira no período de 08 h00 às $08 \mathrm{~h} 30$.

Quando encerrava-se a SEA, os alunos eram divididos em Setores:

- Farmácia - com o objetivo de conhecer a rotina e auxiliar no que fosse necessário; 
- Recepção - conhecer a rotina e auxiliar no que fosse necessário;

- Sala da Enfermeira - auxiliar a Enfermeira em procedimentos diversos;

- Função Volante - aferir pressões arteriais, bem como orientar acerca da Hipertensão e Hipotensão e sobre Alimentação Saudável;

- Sala da Artesã - auxiliar a artesã em atividades de ludoterapia com crianças, adolescentes e adultos que buscavam o serviço, bem como ajudá-la a fazer artesanatos;

- Havia também um momento de conversa com a Psicóloga e a Assistente Social, estas explicando como era desenvolvido o trabalho nessas duas áreas.

Ao término das atividades nos referidos setores, os alunos tinham uma fala crítica reflexiva acerca de suas desenvolturas no dia de estágio, apresentando pontos positivos e negativos de sua postura profissional diária. Após o debate, havia algumas atividades altruístas de reflexão e de desenvolvimento da Inteligência Emocional dos alunos, como leituras de textos e debates, dinâmicas, dramatizações com foco na empatia e humanização, além de estudos de transtornos mentais e filmes (atividade de casa).

O estágio tinha duração de vinte horas semanais tendo sido realizado durante o período de seis semanas. Ao término do estágio, cada aluno fazia sua auto avaliação, refletindo e evidenciando seu desenvolvimento além de compartilhar sua experiência com a professora orientadora.

Os relatos de vivência durante este período foram gratificantes, pois a maioria chegava ao local de estágio, com a percepção errônea de que o tratamento para com o doente mental era baseado no modelo hospitalocêntrico (antes da reforma psiquiátrica) e durante os dias de estágio e no decorrer das atividades/rotina foram mudando essa percepção. A maioria dos estudantes considerou o CAPS como o local de estágio que mais trabalha a humanização e empatia e tido estes, o melhor local de estágio. Além, de relatarem que perceberam um crescimento significativo tanto na vida profissional quanto na vida pessoal durante e após o estágio em Saúde Mental. Todavia, alguns alunos que passaram pelo CAPS não se identificaram/gostaram do local de estágio seja pelas atividades desenvolvidas, seja pela afinidade na área.

Por fim, as atividades propostas e desenvolvidas durante o estágio em Saúde Mental foram realizadas com êxito, pois além da percepção e contribuição para a vida dos estudantes, houve a satisfação e gratidão dos clientes do serviço. 


\section{Conclusões}

O presente estudo teve como objetivo relatar a experiência de estágio em Saúde Mental no Curso Técnico em Enfermagem e servir como guia de atividades para os iniciantes nesta área de atuação e/ou como um instrumento em defesa da Luta Antimanicomial que através dessa rotina, conseguiu-se diminuir o preconceito para com a Saúde Mental, reinserir o cliente em sofrimento psíquico na sociedade e principalmente, reduzir o preconceito para com o tratamento no CAPS.

\section{Referências}

AMARANTE, P. Loucos pela vida: a trajetória da Reforma Psiquiátrica no Brasil. Rio de Janeiro (RJ): Fiocruz; 1995.

BACKES, Marli Terezinha Stein. et al, Apoio à decisão do paciente submetido à cirurgia. Revista Nursing. No 70.p. 43. 2004.

CALOMÉ, Isabel Cristina dos Santos. Et al. O idoso sob a ótica de um grupo de Agentes Comunitários de Saúde - (ACSs) Revista Nursing. No 67. p. 24. 2003.

FINDLAY, Eleide Abril Gordon et al. Guia para a Elaboração de Projetos de Pesquisa. $1^{\circ}$ ed. Joinvelle-SC: UNIVILLE. Atualizada. 2006. p.20.

FREYRE, K. (2004). Era uma vez: Laboratório de Sonhos. Recife: Editora Universidade de Pernambuco. UPE.

HILDEBRAND, Gilberto. Interação e Desenvolvimento Social. In: II Encontro de Extensão UDESC. 2007. Disponível em: 〈www.udesc.br/.../encontro_de_extensao_2006_apresen...>. Acesso em: 10 de Outubro 2017.

HILDEBRAND, Gilberto. Interação e Desenvolvimento Social. In: II Encontro deExtensão UDESC. 2007.2 Disponível em: <www.udesc.br/.../encontro_de_extensao_2006_apresen...>. Acesso em: 10 de Outubro 2017. KESSLER, Marciane; et al. A Educação em Saúde como Instrumento para Prevenção de Doenças Cardiovasculares na População Masculina. Relato de Experiência.

LAKATOS, Eva Maria; MARCONI, Maria Andrade. Metodologia do Trabalho Cientifico. $6^{\circ}$ ed. São Paulo - SP. Atlas. 2002. p. 15 - 32. 
OLIVEIRA, Alice, G.B; ALESSI, Neiry P. O trabalho de enfermagem em saúde mental: contradições e potencialidades atuais. Rev Latino-am Enfermagem 2003 maio-junho; 11(3):333-40

RICHARDSON, R. J. et al. Pesquisa Social: métodos e técnicas. São Paulo: Atlas, 1999.

SEVERINO, A. J. Metodologia do Trabalho Científico. 23. ed. rev. e atual. São Paulo: Cortez, 2007.

SILVA, Kely V.L.G; MONTEIRO, Ana R.M. A família em saúde mental: subsídios para o cuidado clínico de enfermagem. Rev Esc Enferm USP 2011;45(5):1237-42

SIMÕES, ALA; RODRIGUES, FR; TAVARES, DMS; RODRIGUES, LR. Humanização na Saúde: Enfoque na atenção primária. Texto Contexto Enferm. 2007; 16(3):439-44.

ROTELLI, F; LEONARDIS, O; MAURI, D; RISIO C. Desinstitucionalização, uma outra via. A Reforma Psiquiátrica Italiana no contexto da Europa Ocidental e dos “Países Avançados".São Paulo (SP): Hucitec; 1990.

VAITSMAN, Jeni; ANDRADE, Gabriela Rivieres Borges de. Satisfação e Responsividade: Formas de Medir a Qualidade e a Humanização de Assistência à Saúde. Ciência \& Saúde Coletiva, 10(3): $599-613,2005$

VILLELA,S.C; SCATENA,M.C.M. A enfermagem e o cuidar na área de saúde mental. Rev Bras Enferm. 2004;57(6):738-41

ZERBETTO, Sonia Regina; PEREIRA, Maria Alice Ornellas. O Trabalho do profissional de nível médio de enfermagem nos novos dispositivos de atenção em saúde mental. Ver Latino am-Enfermagem 2005 janeiro-fevereiro; 13 (1):112-7 - www.eerp.usp.br/rlae

YAMAZAKI, Sérgio Choiti; YAMAZAKI, Regiani Magalhães de Oliveira. Sobre ouso de metodologias alternativas para ensino-aprendizagem de ciências. In: Educação e Diversidade na Sociedade Contemporânea. Ed. COELHO, N. 2006. Disponível em: <http://fisica.uems.br/profsergiochoitiyamazaki/t5p2metodologias.pdf>.

\section{Como citar este artigo (Formato ABNT):}

MARQUE, Yana Camila Brasil. Saúde mental na Prática. Id on Line Rev.Mult. Psic., 2018, vol.12, n.40, p.163-171. ISSN: 1981-1179.

Recebido: $24 / 02 / 2018$

Aceito 28/02/2018 